\title{
A docência nas séries iniciais do ensino fundamental: reflexões sobre a escolha da profissão e sobre o exercício profissional
}

\author{
Teaching in the initial series of basic education: reflections on \\ the choice of profession and professional practice
La docencia en los niveles inciales de la educación básica: reflexiones sobre la elección de la profesión y el ejercicio profesional

Ana Paula Furtado SoAREs Pontes*

\begin{abstract}
RESUMO
Este artigo discute a iniciação à docência e os dilemas do exercício profissional na visão dos professores das séries iniciais do ensino fundamental de escolas estaduais da Paraíba, onde desenvolve-se um projeto de extensão. A pesquisa, de cunho qualitativo (ALVES-MAZZOTTI, 2002), foi desenvolvida em três escolas públicas, localizadas em João Pessoa, a partir de entrevistas com 11 professores. O artigo traz uma breve discussão acerca da docência como profissão, seguida da análise dos resultados em termos de caracterização dos professores entrevistados, escolha da profissão e exercício profissional. As conclusões avançam no sentido de se compreender que a docência tem perdido conquistas profissionais históricas, chamando-se a atenção para o desafio do resgate da valorização da colegialidade docente e para o fortalecimento da relação entre os pares (IMBERNÓN, 2000) como estratégia importante no fortalecimento da docência como profissão.
\end{abstract}

Palavras-chave: Professores. Profissão docente. Escolha da profissão.

\begin{abstract}
This article discusses teaching initiation and the dilemmas of professional practice in the teachers' view who work in the early grades of primary education in state schools of Paraiba, where we develop an extension project. This qualitative research (ALVES-MAZZOTTI, 2002) was developed in three public schools located in the city of João Pessoa by carrying out interviews with eleven teachers. The article provides a brief discussion on teaching as a profession, and then analyzes the results in terms of characterization of the interviewed teachers, the choice of profession and professional practice. Our findings lead to the understanding that teaching has lost historical professional achievements, calling attention to the challenge of restoring teacher collegiality and the strengthening of the relationship among these peers (IMBERNON, 2000) as an important strategy in consolidating teaching as a profession.
\end{abstract}

Keywords: Teachers. Teaching. Choice of profession.

\section{RESUMEN}

Este artículo discute la iniciación a la docencia y los dilemas en el ejercicio profesional desde el punto de vista de profesores de los niveles iniciales de la educación básica de las escuelas estaduales del estado de Paraíba, en donde llevamos a cabo un proyecto de extensión. El estudio, de orden cualitativo (ALVES-MAZZOTTI, 2002), se desarrolló en tres escuelas públicas, ubicadas en João Pessoa, a partir de entrevistas con once profesores. El artículo presenta una breve discusión sobre la docencia como profesión, seguida de un análisis de los resultados en términos de caracterización de los profesores entrevistados, la elección de la profesión o el ejercicio profesional. Nuestras conclusiones avanzan en el sentido de comprender que la docencia ha perdido conquistas profesionales históricas, llamando la atención hacia el desafío de rescatar la valorización de la colegialidad docente y el fortalecimiento de la relación entre pares (IMBERNÓN, 2000) como estrategia significativa para el fortalecimiento de la docencia como profesión.

Palabras clave: Profesores. Profesión docente. Elección de la profesión.

\footnotetext{
* Doutorado em Educação pela Universidade Federal de Pernambuco, professor Adjunto III da Universidade Federal da Paraíba/Campus I, professora do Programa de Pós-Graduação em Políticas Públicas, Gestão e Avaliação da Educação Superior/UFPB. E-mail: <anaufpb@gmail.com>.
} 


\section{INTRODUÇÃO}

Este artigo tem como objetivo discutir a iniciação à docência e os dilemas do exercício profissional na visão dos professores das séries iniciais do ensino fundamental de escolas estaduais da Paraíba. A pesquisa foi desenvolvida seguindo uma abordagem de cunho qualitativo, pois trabalha-se com crenças, percepções, sentimentos e valores (ALVES-MAZZOTTI, 2002).

O trabalho empírico foi realizado em três escolas públicas da Paraíba, localizadas em João Pessoa, onde se desenvolve um projeto de formação com foco na discussão acerca da docência nas séries iniciais do ensino fundamental. A escolha dessas escolas se deu devido às mesmas estarem entre as instituições que apresentaram resultados abaixo das metas definidas para a $4^{\underline{a}}$ e a $5^{\underline{a}}$ série, segundo o Índice de Desenvolvimento da Educação Básica $^{1}$ (Ideb) de 2011. Em que pese a utilização desse indicador como base para identificar as escolas onde se desenvolve o projeto, não se perde de vista as críticas ao Ideb como modelo de avaliação externa. Com Pacheco (2014), apresenta-se uma das limitações da avaliação externa em Portugal, que pode ser considerada também para a realidade brasileira, o reforço de uma perspectiva de responsabilização do professor e das instituições pelo sucesso ou fracasso de seus alunos, sem se garantir as condições básicas para a ação educativa:

Com efeito, a qualidade das escolas, definidas pelo objetivo de reforçar a responsabilização individual e institucional, para além de valorizar a política de proximidade, com a valorização dos contextos, é associada a mecanismos externos de avaliação e à fixação de metas a cumprir, de modo que a abordagem do currículo seja mais valorizada pelos resultados que pelos processos e mais, ainda, pela avaliação externa que pela avaliação interna (PACHECO, 2014, p. 367).

Nesse sentido, aponta-se a contribuição de Martins (2001, p. 34), que acrescenta:

\begin{abstract}
Mesmo que se considere a realização de avaliação externa sobre os resultados obtidos pelas escolas um importante indicador para que os gestores dos sistemas de ensino possam corrigir problemas e reorientar decisões e percursos institucionais, as metodologias que desconsideram a diversidade cultural que permeia as redes de escolas não captam a efetiva dinâmica das unidades escolares, com base apenas nos resultados finais obtidos por testes padronizados.
\end{abstract}

\footnotetext{
O Ideb é um indicador de qualidade educacional que combina informações de desempenho dos estudantes avaliados pela Prova Brasil, nas áreas de Língua Portuguesa e Matemática, e o fluxo escolar (avaliado pelo Programa Educacenso).
}

No âmbito do projeto, desenvolve-se com os professores das séries iniciais do ensino fundamental discussões, estudos e formações continuadas ao longo do ano letivo de 2012, além de entrevistas sobre a escolha da profissão e sobre o desenvolvimento profissional.

Neste artigo, centra-se a atenção sobre como se deu a escolha da profissão pelos professores e suas reflexões sobre o exercício profissional. Para tal, foram realizadas entrevistas com 11 professores das três escolas envolvidas no projeto. A opção pelo trabalho a partir de entrevista se deu por se entender, com Ribeiro (2008, p. 141), ser esta uma técnica que favorece a obtenção de informações a respeito do objeto deste artigo, o que permitiu " [...] conhecer sobre atitudes, sentimentos e valores subjacentes ao comportamento, o que significa que se pode ir além das descrições das ações, incorporando novas fontes para a interpretação dos resultados pelos próprios entrevistadores".

O estudo está estruturado a partir de uma breve discussão acerca da docência como profissão, seguida da análise dos resultados da pesquisa em termos de caracterização dos professores entrevistados, da escolha da profissão e do exercício profissional.

\section{DOCÊNCIA COMO PROFISSÃO}

No contexto da institucionalização da instituição escolar, a partir da segunda metade do século XVIII, o Estado tomou para si a responsabilidade pela escolarização das crianças, dando início a um processo identificado por Nóvoa (1991) como a gênese do desenvolvimento da docência como profissão. Nesse cenário, o Estado adotou uma série de medidas que visavam à homogeneização e à unificação do ensino que, até então, era ministrado, em sua maioria, por religiosos que assumiam a docência como uma ocupação secundária ou acessória.

Dentre as medidas voltadas para a estatização dos sistemas escolares de maior relevância à época, a principal foi a institucionalização do processo de seleção e recrutamento do pessoal docente mediante a criação de um modelo baseado na licença profissional. De obtenção obrigatória, a licença constituiu-se num suporte legal que autorizava o exercício da atividade docente. Tratava-se, pois, da permissão para ensinar, o que contribuiu para a delimitação do campo social de ensino e, com isto, para o estabelecimento do monopólio pelo grupo (NÓVOA, 1991).

Nesse sentido, passou-se a defender a existência de um corpo de saberes específicos da docência e um conjunto de normas e valores que deveriam nortear a ação docente, sendo estes fortemente influenciados pelas crenças morais e religiosas da época. Nóvoa (1991) assinala que, no processo histórico de desenvolvimento da profissão 
docente, surgem reivindicações socioprofissionais, tais como o reconhecimento do caráter especializado da ação educativa e de sua relevância social.

A defesa da posse de um conjunto de conhecimentos especializados culminou com a criação das escolas normais no século XIX, responsáveis por produzir e reproduzir um corpo de saberes e um sistema de normas próprias que passaram a fundamentar a profissão docente. O processo de consolidação da docência como profissão segue avançando. As conquistas dessa categoria progrediram no sentido da compreensão do profissional. No sentido estrito, evoluíram como um coletivo autorregulado de pessoas que trabalham diretamente para o mercado em uma situação de privilégio monopolista, sendo, assim, protegidas da competição pela lei (PAPI, 2005).

Em que pese não haver consenso sobre as características de uma profissão, destaca-se a compreensão de Enguita (1991) de que os grupos profissionais compartilham cinco delas: competência profissional (obtida mediante formação específica e de longo tempo); vocação (serviço à humanidade, ideal de serviço); licença (campo de atuação exclusivo, reconhecido e protegido pelo Estado); independência (autonomia no exercício profissional perante a organização e os clientes); autorregulação (código de ética, órgãos para resolução de conflitos).

Todavia, é importante destacar que as várias correntes da Sociologia das Profissões não estão de acordo quanto aos critérios pelos quais uma ocupação passa a ser considerada uma profissão. Mas há o entendimento de que a profissionalização é um processo de construção histórica e situada, não há linearidade ou uniformidade no processo, pois não há um caminho único a seguir. Sendo assim, considera-se que a constituição da profissionalização possa ocorrer sem que todas as características supracitadas sejam conquistadas por determinado grupo profissional.

$\mathrm{Na}$ contemporaneidade, o mundo do trabalho tem passado por significativas transformações decorrentes do avanço tecnológico e da globalização do capital, o que tem provocado o redimensionamento do papel da educação e da escola.

No Brasil, as reformas educacionais postas a cabo a partir da década de 1990 tiveram como eixo norteador a adequação do sistema educativo ao atual estágio de desenvolvimento produtivo. Nesse cenário, a docência como profissão obtém destaque, sendo o professor alvo de atenção das políticas educacionais. Por isso, para Nóvoa (1995), o docente é considerado o principal agente da educação, sendo o modelo do professor profissional ressaltado, ganhando espaço a defesa pela valorização de seu estatuto socioprofissional.

O discurso oficial em favor da profissionalização docente, segundo Hypólito (1999), não encontra respaldo na prática. Este possui, na verdade, uma função disciplinadora, controladora e ideológica, uma vez que as condições concretas sobre as quais a atividade docente se realiza se traduzem num processo desqualificador. Para o pesquisador, os professores são submetidos, dentre outros aspectos, ao rebaixamento de salários e à diminuição das chances de acesso aos bens culturais, o que contradiz todo discurso em defesa da profissionalização docente e de sua valorização.

No Brasil, há registros históricos de uma insuficiente formação inicial, baixos salários e precárias condições de trabalho para o exercício da docência (DOURADO, 2001). Tais referências sinalizam para uma aguda proletarização dessa profissão. Dessa forma, não se pode desconsiderar que esse profissional, na atualidade, vem apresentando sinais evidentes de precarização em termos de valorização, prestígio, poder aquisitivo, condições de vida, respeito e satisfação no exercício do Magistério.

Nesse cenário, há sérios indícios de que a docência tem passado por um processo que põe em cheque suas conquistas profissionais, podendo-se afirmar que a profissionalização docente vem perdendo força num contexto de pretensa valorização desse profissional e da educação.

O professor, ao assumir as variadas funções que a escola pública e/ou privada estabelece, acaba por desempenhar papéis que estão fora do seu universo de formação. Oliveira (2003) compreende que tais exigências despertam no docente um sentimento de desprofissionalização, de perda de identidade profissional, além de comprometer o exercício de sua função precípua de ensinar.

Para Nóvoa (1995), o que se verifica na realidade é o acirramento de uma crise da profissão docente que vem de muitos anos e que tem como consequência a desmotivação pessoal e os altos índices de absenteísmo, abandono, insatisfação e indisposição por parte dos docentes.

Os sinais de que a profissão docente está passando por uma crise são, também, ressaltados por Esteve (1995), quando se refere às precárias condições de trabalho a que estão submetidos os/as professores/as, aos seus baixos salários e à desilusão em relação à profissão. Tais situações corroboram para que estes sejam expostos a desequilíbrios psicológicos, estresse, mal-estar docente e sensação de frustração física e emocional.

Convém recolocar-se a problemática da profissionalização docente como um desafio a ser perseguido no coletivo, em que se denunciam as condições a que são submetidos os professores, visando a superar concepções ingênuas e debruçando-se sobre a realidade vivenciada pelos docentes em suas respectivas instituições e redes. E, assim, fortalecer iniciativas de formação e desenvolvimento profissional que assumam como horizonte a educação de qualidade socialmente referenciada. 


\section{A VISÃO DOS PROFESSORES DE ESCOLAS ESTADUAIS SOBRE A PROFISSÃO E SOBRE O TRABALHO QUE REALIZAM}

Neste item, apresenta-se a caracterização do perfil dos sujeitos entrevistados ${ }^{2}$. Na sequência, discute-se a inserção dos professores no fazer docente, lançando um olhar sobre a escolha da profissão, sobre as dificuldades que encontraram no exercício da docência e sobre os desafios que enfrentam no cotidiano escolar.

\section{CARACTERIZAÇÃo DOS PROFESSORES}

Das três escolas estaduais lócus da pesquisa, 11 professores/as foram entrevistados/as, do/as quais, apenas um era do sexo masculino. Do total, cinco possuíam graduação em Pedagogia; uma, em Filosofia; uma, em Ciências Biológicas e quatro professoras possuíam Magistério, sendo uma contratada há 23 anos, como prestadora de serviço, o que denota uma grave e clara inobservância aos requisitos legais para admissão de servidores públicos:

\begin{abstract}
"Eu comecei no estado, em 1986, entrei por acaso, como prestadora de serviço, me acomodei, 23 anos como prestadora. Tenho muitas amigas aqui, todas são nota 10 pra mim, sempre me ajudaram. E eu estou aqui querendo que Deus me ajude pra me aposentar, porque eu não tenho mais estrutura pra estudar pra concurso." (Professora 7, Licenciada em Filosofia, Escola 3)
\end{abstract}

Dentre quatro docentes do quadro temporário com mais tempo na função, o caso da professora sob o regime de contrato temporário há 23 anos chama a atenção. Verifica-se, com isso, o não atendimento da exigência de provimento de cargos públicos pela via do concurso, tendo a Secretaria do Estado da Educação (SEE) da Paraíba lançado mão do artifício da contratação temporária por muito tempo, o que só vem sendo revisto mais recentemente com o concurso público de $2012^{3}$. Assim, a SEE burlou por muitos anos o que preceitua a Constituição Federal de 1988 (CF 1988), em seu art. 37, inciso II: “[...] a investidura em cargo ou emprego público depende de aprovação prévia em concurso público de provas ou de provas e títulos, de acordo com a natureza e a complexidade do cargo ou emprego" (BRASIL, 1988).

\footnotetext{
2 Para efeito de identificação dos entrevistados, suas falas são representadas no texto por "Professor" ou "Professora" identificados/as com os números de 1 a 11, seguidos/as da sua respectiva titulação e identificação da escola em que atuam, com a numeração de 1 a 3.

3 No ano seguinte à conclusão do projeto, ocorreu o concurso para ingresso no cargo de Professor de Educação Básica 3 da Carreira do Magistério Estadual, no âmbito da Secretaria de Estado da Educação. E seu resultado foi divulgado em janeiro de 2013, dando-se início ao processo de convocação dos professores em substituição ao quadro temporário e ao preenchimento de novas vagas.
}

Outrossim, os contratos de professores/as em regime temporário reiteradas vezes contrariam também o art. 37, inciso XI da CF (1988), que permite a contratação por tempo determinado de servidores, para atender à "[...] necessidade temporária de excepcional interesse público". Ora, se o contrato temporário vinha sendo sucessivamente prorrogado, não se configuraria uma excepcionalidade, implicaria, sim, a necessidade de concurso.

É importante destacar que tal situação ocorrida à época, no estado, também foi verificada no país como um todo, uma vez que, segundo o Censo Escolar 2012, a Paraíba, com 51,9\%, foi um dos sete estados brasileiros onde prevaleceu um maior número de professores com contrato temporário em comparação com a quantidade de contratos efetivos. O que foi superado apenas por Espírito Santo (71\%), Mato Grosso (66,1\%), Acre (62,9\%), Ceará $(60,2 \%)$, Mato Grosso do Sul $(60,1 \%)$ e Santa Catarina (59,8\%) (BRASIL, 2012).

Entretanto, em maio de 2013, a Secretaria de Educação da Paraíba refutou tal informação, justificando que os números do Censo 2012 estariam desatualizados, uma vez que, com o concurso de 2012, haveria $13 \mathrm{mil}$ concursados $(51,9 \%)$ na rede, contra 8 mil professores temporários. Quanto à possiblidade de substituição desse enorme contingente de temporários remanescentes, a então Secretária de Educação justificou a necessidade de se fazer uma avaliação financeira do estado em conjunto com as secretarias de Administração, Finanças e Planejamento para poder traçar as necessidades de seleção e contratação de servidores (FOCANDO A NOTICIA, 2013).

Nesse sentido, pode-se inferir que a permanência de 8 mil professores temporários na rede se mostra mais interessante sob o ponto de vista econômico. Isso porque, em muitos casos, eles são contratados por um prazo determinado e limitado ao ano letivo, sem contar com o registro na Carteira de Trabalho e Previdência Social e sem a garantia do recolhimento do Fundo de Garantia por Tempo de Serviço, além de receberem apenas as horas trabalhadas no período de seu contrato.

Outro fato que chamou a atenção foi o depoimento do único docente do sexo masculino entrevistado, que mencionou ter se iniciado na docência, mesmo sem haver concluído o curso de Magistério, para substituir sua esposa que iria se submeter a uma cirurgia. A iniciativa de convidá-lo para reger a sala teria sido da própria diretora da escola, e ele aceitou, justificando que assim ela não perderia o salário. Isto indica que tal procedimento não seguiu os trâmites legais para liberação da licença médica remunerada, tampouco a substituição de docentes afastados, medidas previstas para qualquer trabalhador com contrato de trabalho formal: 
"Eu estava terminando o Magistério. Minha esposa era professora da escola que eu trabalho hoje e ela precisou fazer uma cirurgia e ficar três meses afastada da sala de aula. E a diretora me chamou e disse: 'Assuma a sala de sua esposa, de Ciências'. Aí, eu disse: 'Eu não tenho condição, o meu curso é Magistério e o da mulher é Ciências'. Ela disse: 'Eu não quero nem saber, vá pra casa e de tarde, quando eu voltar, quero você dentro de sala de aula'. Aí minha mulher disse: 'É um desafio, vá, se apresente, que eu vou preparar as aulas pra você começar a trabalhar'. Porque se ela passasse pra outra pessoa a gente perdia o salariozinho de 400 reais na época, né? Foi difícil porque eu nunca tinha entrado numa sala do fundamental e comecei a trabalhar, muito nervoso, suava mais do que vara verde." (Professor 4, Magistério e Ciências Biológicas, Escola 2)

Identifica-se, nesse depoimento, um aspecto que contraria a principal característica da docência como profissão, pois não se atendeu à exigência de formação longa específica para autorizar a atuação como docente em determinada área, no caso Licenciatura em Ciências Biológicas, para lecionar no ensino fundamental II. Ora, se foi permitido pela gestora da instituição uma pessoa sem habilitação "assumir a sala" de uma professora em processo de afastamento, mesmo que temporariamente, isso reflete uma postura de desqualificação do exercício profissional docente. Nesses termos, essa atitude da gestora contraria o entendimento da docência como uma profissão complexa, que requer formação de nível superior específica.

Percebe-se que, motivada pela necessidade de garantir sua remuneração, a própria professora aceitou a ideia de que o marido lecionasse sem ter tal formação e, para ajudá-lo, tomou a iniciativa de preparar as aulas, que ele deveria seguir. Sua atitude permite inferir que ela mesma encara a função docente como comparável à de técnicos, reduzidos a meros executores de procedimentos pedagógicos (TARDIF, 2002), sendo, por isso, considerada uma ocupação limitada em sua autonomia e especialização.

Dito de outro modo, a opção por substituir um docente por uma pessoa sem formação específica, mesmo que por curto período de tempo, vai de encontro à principal medida tomada em direção à constituição da docência como profissão - a licença profissional, criada desde a segunda metade do século XVIII pelo Estado. Segundo Nóvoa (1991), a instituição da licença foi um marco decisivo para a evolução da docência como profissão, sendo uma condição obrigatória para o exercício profissional. À época, foi definida como

[...] Um documento em geral, concedido à saída de um exame ou de um concurso, aos quais podem se apresentar todos os indivíduos que preencham um certo número de condições de entrada e de admissão (habilitações literárias, idade, bom comportamento moral, etc.): constitui-se num verdadeiro suporte legal para o exercício da atividade docente, na medida em que contribui para a delimitação do campo social do ensino e para a monopolização deste domínio por um grupo profissional cada vez mais definido e enquadrado (NÓVOA, 1991, p. 122).

Nesses termos, a licença é reconhecida como o primeiro passo no processo de profissionalização docente, uma vez que foi a partir de sua instituição que foram criadas as condições para a "elaboração de um cânon de competências técnicas baseadas em critérios escolares", que serviu de base para o recrutamento dos docentes e para o esboço de uma carreira docente, aspectos fundamentais para a afirmação da categoria como grupo profissional (NÓVOA, 1991, p. 122).

Diante dessa discussão sobre a importância da licença profissional para a consolidação da docência como profissão, compreende-se a gravidade da iniciativa da gestora da escola 2 em substituir uma professora, afastada para tratamento de saúde, por uma pessoa não regularmente habilitada. Houve, assim, o negligenciamento de uma condição fundamental para o exercício da profissão: a licença profissional.

\section{A ESCOLHA DA PROFISSÃo}

Em termos de tempo de docência, oito docentes afirmaram possuir mais de 23 anos de experiência. Dois outros, pouco mais de cinco anos, e um docente não prestou tal informação. Nesse sentido, identificou-se que o grupo de docentes participantes do projeto era formado por pessoas com longa experiência na área. Possuíam, em sua maioria, mais de 50 anos de idade, havendo apenas três docentes na faixa etária de 25 a 35 anos.

A maioria das professoras afirmou que a escolha da profissão foi motivada pela necessidade de inserção no mercado de trabalho:

\begin{abstract}
"Quando eu fui fazer o pedagógico, foi porque o desemprego estava grande. Eu não levava jeito no comércio. Aí, fui fazer o pedagógico, fui fazer um curso lá em Sapé. Aí, ganhei uma bolsa de seis meses e fui pra escola no bairro onde eu morava e a diretora gostou muito do meu trabalho e disse que ia arrumar uma sala pra mim, daí até hoje." (Professora 9, Magistério e Pedagogia, Escola 3)
\end{abstract}

O depoimento da Professora 9 reflete o entendimento de que a opção pela docência se dá, muitas vezes, pelo interesse em conquistar um emprego, não necessariamente pela atividade docente em si. De forma similar, Tartuce, Nunes e Almeida (2010, p. 451) dão conta de que, para alguns estudantes, 
[...] a atividade docente apresenta alguma possibilidade de oferta de trabalho a partir de um curso de formação considerado acessível, o que faz com que alguns alunos ingressem em cursos superiores de Pedagogia ou licenciatura sem real interesse em atuar como professor.

Entretanto, a despeito da forma de ingresso na profissão, muitas professoras entrevistadas afirmaram que desenvolveram o gosto pela profissão durante a experiência que tiveram como docentes. Com isso, entende-se que os professores vão construindo sua identidade profissional ao longo da sua vida, podendo passar a se identificar com a profissão e se engajar no processo de desenvolvimento profissional. Como assinala Papi (2005), a identidade profissional se inicia desde a escolha da profissão, mas perpassa toda a formação inicial e continuada, contemplando experiências diversas a que se tem acesso em diferentes espaços institucionais.

Nesse sentido, a identidade profissional resulta de um processo de construção inacabada que percorre toda a vida profissional do indivíduo. Assim, ao longo da existência se passa por um processo rico e diverso de socialização em que a identidade se constrói como um “[...] resultado simultaneamente estável e provisório, individual e colectivo, subjectivo e objectivo, biográfico e estrutural, dos diversos processos de socialização que, em conjunto, constroem os indivíduos e definem as instituições" (DUBAR, 1997, p. 105).

Ainda no que se refere à escolha da profissão, uma das entrevistadas assinalou como motivação o fato de se poder conciliar a vida familiar com a profissional, optando-se por uma jornada de trabalho em apenas um turno, como destacado abaixo:

"Eu fiz vestibular pra Pedagogia. Mas fiz porque algumas professoras me incentivaram dizendo que ganhava o que eu ganhava no comércio, mas tinha a vantagem de não trabalhar no sábado, não trabalhar no domingo, o dia todo. Então eu passei, gostei do curso. Quando terminei fui logo procurar um colégio pra trabalhar. Não ganhava tanto, mas tinha seus benefícios. Depois me casei e vi que o melhor mesmo era ser professora porque assim podia cuidar do marido, dos filhos e dar aula.” (Professora 5, Pedagoga, Escola 2).

Assim, a despeito da baixa atratividade da carreira docente retratada em estudos como o de Tartuce, Nunes e Almeida $(2010)^{4}$, essa profissão tem se mostrado uma

\footnotetext{
${ }^{4}$ A baixa atratividade da docência foi tratada por Tartuce, Nunes e Almeida (2010) em pesquisa recente, realizada nas cinco regiões do país, em diferentes cidades de grande ou médio porte. $\mathrm{O}$ estudo destaca que a carreira docente apresenta menor interesse pelos entrevistados. Segundo as pesquisadoras, o fato de a profissão docente estar associada ao papel feminino e ao cuidado, características assinaladas como naturais e inatas, contribui para que seja associada ao sexo feminino, dificultando a escolha masculina pela carreira.
}

opção para quem tem interesse em trabalhar em apenas um turno. Aspecto ressaltado como importante para algumas mulheres professoras que buscam conciliar sua vida profissional com a maternidade e com outras atividades cotidianas.

Entretanto, essa opção não é uma prática usual para a maioria dos docentes, uma vez que, mesmo com a implementação do Fundo de Manutenção e Desenvolvimento da Educação Básica e Valorização dos Profissionais da Educação (Fundeb) ${ }^{5}$ e do Piso Salarial Nacional (Lei n ${ }^{\circ} 11.738 / 2008$ ), o padrão de vida dos professores não sofreu mudanças significativas, como destaca Gurgel (2012, p. 97) ao discutir a situação do Magistério da educação básica paraibana no contexto das políticas educacionais:

[...] embora o crescimento da arrecadação de impostos contribua para a recuperação salarial do magistério da rede estadual, a pequena recuperação salarial repercutiu insuficientemente na melhoria do padrão de vida dos docentes, que continuam exercendo múltiplas jornadas de trabalho para sobreviver.

Não obstante, apesar dos baixos salários, por pertencerem a estratos sociais menos favorecidos, algumas professoras veem essa oportunidade como uma conquista financeira, como destacado a seguir:

As conquistas financeiras, eu acho que não é muito não, viu? Eu acho que a minha conquista foi uma conquista assim, de mim mesma. Uma conquista que me satisfez muito. Assim, de eu ter o meu dinheiro. Não é muito, a gente sabe. Mas eu conquistei muita coisa assim, que eu posso ajudar a minha família (Professora 2, Magistério, Pedagogia e Especialização, Escola 1).

Percebe-se que a docência tem despertado interesse maior para segmentos socioeconômicos menos favorecidos, sendo esses jovens, muitas vezes, os primeiros da família a conquistar diplomas de curso superior. Os dados do Relatório Síntese do Exame Nacional de Desempenho dos Estudantes de 2011 (Enade/2011) trazem referências que corroboram com tal informação, pois, considerando a distribuição da faixa de renda mensal familiar dos estudantes concluintes de Pedagogia (Licenciatura) que realizaram o exame em 2011 (85.428 inscritos), 35,5\% declararam possuir renda familiar de 1,5 a 3 salários mínimos ( $\mathrm{R} \$ 817,01$ a $\mathrm{R} \$$ $1.635,00)$, sendo seguidos por $23,3 \%$ de estudantes com

\footnotetext{
5 O Fundeb foi criado pela Emenda Constitucional no 53/2006, regulamentado pela Lei $n^{0}$ 11.494/2007 e pelo Decreto $n^{\circ}$ - 6.253/2007, com o objetivo de investir na educação infantil, no ensino médio e na educação de jovens e adultos, em substituição ao Fundef (Fundo de Manutenção e Desenvolvimento do Ensino Fundamental e de Valorização do Magistério), criado para atender ao ensino fundamental.
} 
renda variando de 3 a 4,5 salários mínimos ( $\mathrm{R} \$ 1.635,01$ a R \$ 2.452,00). Outro aspecto destacado nesse relatório é que $78,3 \%$ desses concluintes realizaram todo o ensino médio em escola pública.

Diante de tal panorama, Tartuce, Nunes e Almeida (2010) ressaltam que a prevalência de estudantes de estratos sociais menos favorecidos em cursos de formação de professores permite considerar que os mesmos tiveram dificuldades de várias naturezas para chegar ao ensino superior, passando por inúmeras restrições financeiras, o que compromete seu contato com experiências culturais variadas e o consequente acesso a bens culturais. Nesse sentido, os cursos de formação inicial de professores precisam considerar o perfil dos estudantes, de forma a, como destaca Gatti (2014, p. 49), reconhecer que

É com esse background dos estudantes que os docentes nas licenciaturas devem trabalhar; por essa razão, é importante ter bons planejamentos curriculares e didáticos, com a criação de estímulos culturais e aproveitamento da motivação que esses segmentos portam. Para tanto, porém, é necessário não só um envolvimento pedagógico adequado com os licenciandos como também um projeto institucional para o acolhimento e formação desses alunos.

Em alguns depoimentos das entrevistadas é possível inferir que a docência seria identificada como uma profissão feminina, discurso que se fortaleceu nas primeiras décadas do século XX, no Brasil, associando-se o ensino primário a características consideradas femininas (CARVALHO, 1998). Entretanto, isso nem sempre foi assim. Até os anos finais do século XIX, a docência era considerada uma profissão masculina, situação que aos poucos foi se modificando.

Sobre essa problemática, Louro (2001) destaca que não apenas no Brasil, mas em muitas outras sociedades, a atividade docente foi iniciada por homens

[...] aqui, por religiosos, especialmente jesuítas, no período compreendido entre 1549 e 1579 . Posteriormente, foram os homens que se ocuparam com mais frequência, tanto como responsáveis pelas 'aulas régias' - oficiais - quanto como professores que se estabeleciam por conta própria (LOURO, 2001, p. 449).

Para Enguita (1991), tal mudança se deu, inicialmente, por se compreender o ensino como uma das atividades extradomésticas aceitas para as mulheres pela ideologia patriarcal da época. Como consequência, gerou-se o entendimento de que se pagariam baixos salários às professoras, por considerar uma atividade transitória ou mesmo uma segunda fonte de renda.

Com isso, nos finais do século XIX, as escolas normais brasileiras já registravam uma elevação considerável no número de mulheres matriculadas, tendo os homens buscado melhores empregos em ramos de atividade industrial, em meio ao contexto marcado pelo processo de industrialização brasileiro que se avizinhava, passando o Magistério a ser identificado como um trabalho de mulher (LOURO, 2001).

Nesses termos, o entendimento de que a docência é uma atividade destinada às mulheres deve ser revista, pois não há qualquer sustentação para se afirmar que haveria uma determinação profissional segundo os estereótipos de gênero. Há que se compreender o caráter histórico e social das diferenças entre os homens e as mulheres, investindo-se na superação desses estereótipos. Até porque as professoras que se percebem como "mulheres educadoras natas" tendem a distanciar-se da compreensão da docência como profissão.

Entretanto, é importante salientar que, apesar de a maioria dos docentes entrevistados destacarem as dificuldades pelas quais passaram no exercício de sua profissão, esses professores ressaltam o sentimento de amor pelo trabalho que realizam. Assumem a docência, em alguns casos, como uma questão vocacional, seguindo um viés de "chamamento" que se assemelha a uma perspectiva presente na origem da docência como profissão, quando a docência seguia o modelo de sacerdócio. Assumida como uma prestação de serviço abnegada, que implica sacrifício e doação, tal compreensão pode ser percebida nos seguintes depoimentos:

\footnotetext{
"Eu acho que foi plano de Deus estar aqui dentro porque eu nunca pensei em estar aqui dentro. Eu fiz o curso de Licenciatura em Filosofia, aprendi a ensinar e acho que entrei aqui mais por parte afetiva com aluno. Não sou professora nota 10, mas o que eu posso fazer, eu faço. Me doo demais também. Tenho meus alunos como filhos. Luto por eles, tenho aluno formado, outros que nem conheço, mas sou uma pessoa realizada porque acho que fiz de coração. Só me sinto um pouco desvalorizada porque só ganho um salário mínimo e a gente não tem nem esses estímulos todos pra dar aula. Eu sempre ajudei aqui muito aluno, cansei de levar mais de 20 pra Igreja, fazia trabalho comunitário. Por isso que eu digo que foi plano de Deus. Muitos não foram, mas a semente foi plantada. Mas eu amo de coração meus alunos." (Professora 7, Licenciada em Filosofia, Escola 3).
}

"Eu mesma que tinha aquela vocação. Eu tinha a maior vontade, eu brincava com as minhas bonecas. As bonecas eram alunas e eu era a professora. Era só isso, o resto, só sei que eu gostava muito." (Professora 1, Magistério, Escola 1).

Nesse sentido, reporta-se a Nóvoa (1991), quando discute sobre a definição do conjunto de normas e valores que nortearam a docência como profissão desde 
o século XVIII. O pesquisador afirma que tal definição foi fortemente influenciada por crenças morais e religiosas, que comprometeram a passagem da docência de "missão religiosa de educar os jovens" à "prática de um ofício e da vocação sustentada por um apelo a uma profissão". Assim, como nos depoimentos das Professoras 1 e 7, entendese que não desapareceram as motivações originais da docência, tendo esse modelo permanecido muito próximo ao daquele do padre (NÓVOA, 1991, p. 119-120).

Diante de referências à ideia de vocação assumida como um dom inato por algumas professoras entrevistadas, ressalta-se o risco de elas assumirem uma perspectiva de trabalho de cunho assistencialista. E, assim, conclui-se com Alves (2006, p, 12):

Porém, se temos que reconhecer a importância dessa chamada vocação, torna-se fundamental desmistificar a sua naturalização: vocação não é um dom inato, mas uma capacidade de realizar bem o trabalho, de superar as dificuldades e lutar pela qualidade da educação. Então, é uma característica profissional aprendida e desenvolvida com muito esforço e estudo.

\section{O PROFESSOR E O EXERCÍCIO DA PROFISSÃO}

Os docentes entrevistados fizeram referências às dificuldades no exercício da profissão, sendo destacados, como principais, a falta de motivação dos alunos, a violência que permeia o espaço escolar, bem como a ausência de assistência dos pais na educação de seus filhos. Apesar das dificuldades apresentadas, todos os entrevistados revelaram que o trabalho que realizam trouxe conquistas profissionais e pessoais. Em geral, apresentaram contentamento pelo reconhecimento que sentem da parte dos ex-alunos que encontraram em algum momento de suas vidas ou alegria de perceber o avanço da aprendizagem dos alunos, como verificado a seguir:

\footnotetext{
"A gente fica orgulhosa, você chegar numa instituição, assim, num hospital, e encontrar uma pessoa assim trabalhando e dizer: 'Ah, professora, quanto tempo!'. Ela já trabalhando como enfermeira ou como outros profissionais. $\mathrm{Eu}$ estou sempre encontrando com alunas minhas. Aí você vê lá sua contribuição, que você ajudou na formação. É muito gratificante isso." (Professora 3, Pedagogia, Escola 1).
}

Em que pese o grave sentimento de perda de prestígio profissional, os docentes ainda relutam em afirmar a validade e o sentido do trabalho que realizam: "A importante missão que lhes incumbe" (GIMENO SACRISTÁN, 1999). Entretanto, é importante considerar que a satisfação que a docência traz aos professores não deve fazê-los perder de vista que este é um trabalho profissional, o que implica a necessidade de se garantir condições dignas de trabalho e valorização profissional.

Diante das considerações postas, observam-se as contribuições de Kuenzer e Caldas (2009), quando discutem o trabalho docente: comprometimento e desistência ${ }^{6}$. As pesquisadoras ressaltam que as condições em que os professores desenvolvem seu trabalho na atualidade provocam sofrimento psíquico, sentimentos de desistência e resistência. Em seus achados, houve destaque para os seguintes fatores: desvalorização da educação; condições de trabalho; carga mental do trabalho; relações sociais no trabalho; políticas nacionais e o controle sobre o trabalho docente; e, por fim, a problemática da violência e da segurança.

A pesquisa possibilitou reconhecer os sentimentos de comprometimento e desistência, assinalados pelos autores, pois é notória a compreensão de que o profissional docente, na atualidade, vem apresentando sinais evidentes de precarização em termos de valorização, prestígio, poder aquisitivo, condições de vida, respeito e satisfação no exercício do Magistério (LÜDKE e BOING, 2004). Entretanto, com Kuenzer e Caldas (2009, p. 48), entende-se que o grande desafio é

\begin{abstract}
[...] enfrentar coletivamente esses problemas que invadem os poros do cotidiano escolar, sem o que não é possível fecundar as condições de resistência da perspectiva da construção de uma escola de qualidade para o conjunto da população. Ou seja, como construir relações e condições de trabalho que garantam efetivamente a possibilidade de transformar em prática o discurso de transformação da escola (KUENZER e CALDAS, 2009, p. 48).
\end{abstract}

\section{CONSIDERAÇÕES FINAIS}

Nesta pesquisa, identificou-se que a equipe docente do ensino fundamental I das três escolas, onde foi realizado o trabalho empírico, era formada por 10 professoras e por um professor. Apesar de a maioria possuir graduação em Pedagogia, registrou-se a existência de quatro professoras apenas com o Magistério.

Outro aspecto que chamou a atenção foi o fato de quatro docentes pertencerem ao quadro temporário dessas escolas, uma delas por 23 anos, num claro desrespeito ao que prevê a Constituição Federal, quanto à forma de provimento de cargos públicos e à exigência de contratação por tempo determinado apenas para atender à necessidade temporária "de excepcional interesse público" (BRASIL, 1988).

\footnotetext{
${ }^{6}$ Os estudos têm por base o trabalho empírico realizado na rede municipal de Curitiba/PR, em que foram entrevistados 12 professores sobre as condições que levam professores à desistência.
} 
No que se refere à escolha da profissão, houve destaque para motivações relacionadas ao entendimento de que a docência apresenta maiores oportunidades de trabalho. O interesse se deu ainda pela expectativa de conquista de um emprego público, além do fato de o exercício dessa atividade poder ocorrer em apenas um turno e, assim, permitir às professoras conciliarem sua vida profissional e pessoal.

Contudo, convém considerar que o interesse pelo trabalho em apenas um turno não é uma opção viável para muitos docentes, uma vez que os baixos salários a que são submetidos levam muitos deles a ter de trabalhar em dois ou três turnos. Segundo Gurgel (2012), apesar da recuperação salarial do Magistério da educação básica paraibana com o Fundeb, a situação não sofreu mudanças significativas.

De outra forma, os resultados apontaram para o fato de que a maior parte do corpo docente pertence a estratos sociais menos favorecidos, o que se refletiu na valorização da conquista de um cargo público, mesmo sendo este na condição de contrato temporário. Na visão das entrevistadas, mesmo reconhecendo que recebem baixos salários, o emprego representou uma conquista no campo financeiro.

Destaca-se também o fato de um docente ter se iniciado na docência sem a titulação específica para a área, sendo um caso claro de negligenciamento de uma condição fundamental para o exercício da profissão: a licença profissional.

A despeito de a maioria das professoras não ter optado pela docência por uma identificação com a profissão, mas pela expectativa de inserção laboral, as mesmas ressaltaram que desenvolveram gosto pela profissão, passando a se comprometer com o trabalho que realizam.

Outro aspecto que se refletiu nas falas dos entrevistados foi a associação da profissão docente a um trabalho destinado a mulheres, numa pretensa determinação profissional segundo os estereótipos de gênero. Nesse sentido, destaca-se a necessidade de se investir na superação desses padrões, afastando-se do modelo de docência como um dom inato, uma vocação ressaltada em alguns depoimentos das entrevistadas.

Defende-se que o entendimento da docência como vocação seja superado, aprofundando-se a compreensão da prática do ensino como profissão e, por isso, devendo ser assumida como um projeto de desenvolvimento profissional que requer formação séria e compromisso individual, coletivo e institucional com o pensar e fazer educação de qualidade socialmente referenciada.

As dificuldades encontradas no exercício da profissão mais ressaltadas nas entrevistas foram a falta de motivação dos alunos, a violência que permeia o espaço escolar e a ausência de assistência dos pais na educação de seus filhos. Entretanto, o sentimento de frustração dos professores é superado pela satisfação sentida perante o reconhecimento e valorização de ex-alunos pelo trabalho que realizam. Diante desses depoimentos, conclui-se que a satisfação no trabalho docente não está relacionada apenas às condições salariais e de trabalho, pois as pessoas necessitam dar um sentido ao que fazem, sendo uma atividade que se dá a partir da interação com outras pessoas: "Os alunos, os colegas, os pais, os dirigentes da escola, etc.” (TARDIF e LESSARD, 2005, p. 38).

A partir das referências postas, compreendem-se alguns desafios da docência nas séries iniciais do ensino fundamental das escolas com baixo Ideb, onde realizouse a pesquisa, remetendo a reflexões importantes sobre a escolha da profissão e sobre o exercício profissional desses professores. Isso, em meio ao panorama marcado pela compreensão ainda presente nas escolas da docência como um dom inato e ao quadro de precarização em termos de valorização, poder aquisitivo, condições de vida e regime de contratação a que são submetidos.

Entende-se que tal panorama, além de se refletir em um processo de precarização do trabalho docente, compromete em alguma medida a qualidade de trabalho pedagógico que esses professores realizam. Outrossim, compromete sobremaneira sua inserção social como profissionais, levando a um movimento que tende, se não à desprofissionalização, à perda de conquistas profissionais históricas da categoria.

Dito de outra forma, o panorama a que se refere impacta fortemente o processo de profissionalização docente em sua direção e força. $\mathrm{O}$ isolamento profissional e a necessidade de sobrevivência dificultam o seu envolvimento com as questões centrais da profissionalização docente.

Nesses termos, é mister que se rompa com o fatalismo que imobiliza a categoria docente e reforça a precarização docente, impulsionando os profissionais em direção ao isolamento ou ao enfrentamento da problemática de forma individualizada. Resta dar visibilidade às estratégias de sobrevivência dos professores e fortalecer processos de organização e resgate da docência como profissão:

No fundo, o que está em causa é a possibilidade de um desenvolvimento profissional (individual e coletivo), que crie condições para que cada um defina os ritmos e os percursos da sua carreira e para que o conjunto dos professores projete o futuro desta profissão, que parece reconquistar, neste final de século, novas energias e fontes de prestígio (NÓVOA, 1999, p. 30).

Assim, tem-se o desafio a ser assumido para além da dimensão do indivíduo, uma vez que este implica uma ação em direção à profissionalização de um e de todos. Há, pois, que se avançar no sentido de contribuir para o debate 
em busca da superação da passividade crítica que paralisa professores e professoras, visando a superar o isolamento profissional, as iniciativas pessoais e individualizantes tão ressaltadas pela lógica neoliberal. Para tal, é fundamental se resgatar o sentido da valorização da colegialidade, da cooperação e do fortalecimento da relação entre os colegas de profissão (IMBERNÓN, 2000), na escola e nos diversos espaços de formação e de convivência dos professores.

\section{REFERÊNCIAS}

ALVES, Nancy Nonato de Lima. Amor à profissão, dedicação e o resto se aprende: significados da docência em educação infantil na ambigüidade entre a vocação e a profissionalização, 2006. $29^{a}$ REUNIÃO ANUAL DA ASSOCIAÇÃO NACIONAL DE PÓS-GRADUAÇÃO E PESQUISA EM EDUCAÇÃO, 2006, Caxambu, MG. Anais da ... Caxambu: Anped, 2006, p. 1-17. Disponível em: <http://www.anped.org.br/ reunioes/29ra/trabalhos/trabalho/GT07-2570--Int.pdf $>$. Acesso em: 02 fev. 2015.

ALVES-MAZZOTTI, Alda Judith. O método nas ciências sociais. In: ALVES-MAZZOTTI, Alda Judith; GEWANDSZNAJDER, Fernando. $\mathbf{O}$ método nas ciências naturais e sociais: pesquisa quantitativa e qualitativa. São Paulo: Pioneira Thompson Learning, 2002.

BRASIL. Constituição da República Federativa do Brasil de 1988. Brasília, DF: Senado Federal: Centro Gráfico, 1988.

Lei no 9.394, de 20 de dezembro de 1996.

Ministério da Educação. Instituto Nacional de Estudos e Pesquisas Educacionais Anísio Teixeira - Inep. Relatório Síntese: Pedagogia (Licenciatura). Brasília, DF, 2011. Disponível em: < http://download.inep.gov.br/educacao superior/enade/relatorio_sintese/2011/2011_rel_pedagogia. pdf $>$. Acesso em: 12 fev. 2015.

BRASIL. Ministério da Educação. Instituto Nacional de Estudos e Pesquisas Educacionais Anísio Teixeira (Inep). Microdados do Censo Escolar da Educação Básica, 2012, Brasília, DF: MEC/Inep, 2012. Disponível em: <http://portal.inep.gov.br/ basica-levantamentos-acessar>. Acesso em: 20 fev. 2015.

CARVALHO, Marília Pinto de. Vozes masculinas numa profissão feminina. Revista Estudos Feministas, Rio de Janeiro, IFCS/UFRJ, v. 6, n. 2, 1998.

CONTRERAS, José. Autonomia de professores. São Paulo: Cortez, 2002.

DOURADO, Luiz Fernandes. A reforma do Estado e as políticas de formação de professores nos anos 1990. In: DOURADO, Luiz Fernandes; PARO, Vitor Henrique (Org.). Políticas públicas \& educação básica. São Paulo: Xamã, 2001.

DUBAR, Claude. A socialização: construção das identidades sociais e profissionais. Porto: Porto Editora, 1997.

GATTI, Bernadete. Formação inicial de professores para a educação básica: pesquisas e políticas educacionais. Est. Aval. Educ., São Paulo, v. 25, n. 57, p. 24-54, jan.-abr. 2014. Disponível em: <http://www.fcc.org.br/pesquisa/publicacoes/ eae/arquivos/1899/1899.pdf>. Acesso em: 15 fev. 2015.
ENGUITA, Mariano Fernández. A ambiguidade da docência: entre o profissionalismo e a proletarização. Teoria \& Educação, Porto Alegre, n. 4, p. 41-61, 1991.

ESTEVE, José Manuel. Mudanças sociais e função docente. In: NÓVOA, António (Org.). Profissão professor. Porto: Porto Ed., 1995. p. 93-124.

FREIDSON, Eliot. Renascimento do profissionalismo: teoria, profecia e política. São Paulo: Editora da Universidade Federal de São Paulo, 1998.

RIBEIRO, Elisa Antônia. A perspectiva da entrevista na investigação qualitativa. Evidência: olhares e pesquisa em saberes educacionais, Araxá/MG, n. 04, p.129-148, maio 2008.

SACRISTÁN, Juan Gimeno. Consciência e acção sobre a prática como libertação profissional dos professores. In: NÓVOA, A. (Org.). Profissão professor. Porto, Portugal: Porto Editora, 1999. p. 63-92

HYPOLITO, Álvaro M. Trabalho docente e profissionalização: sonho prometido ou sonho negado? In: VEIGA, Ilma P. A.; CUNHA, Isabel da (Org.). Desmistificando a profissionalização do magistério. Campinas: Papirus, 1999. p. 81-100.

IMBERNÓN, Francisco. Formação docente e profissional: formar-se para a mudança e a incerteza. São Paulo: Cortez, 2000 .

KUENZER, A.; CALDAS, A. Trabalho docente: comprometimento e desistência. In: FIDALGO, F.; OLIVEIRA, M.; FIDALGO, N. (Org.). A intensificação do trabalho docente: tecnologias e produtividade. Campinas: Papirus, 2009. p. 19-48.

LIBÂNEO, José Carlos. Organização e gestão da escola: teoria e prática. Goiânia: Alternativa, 2001.

LOURO, Guacira Lopes. Mulheres na sala de aula. In: DEL PRIORE, Mary (Org.). História das mulheres no Brasil. São Paulo: Contexto, 2001. p. 443-481.

LÜDKE, Menga; BOING, Luiz Alberto. Globalização e educação: precarização do trabalho docente II - caminhos da profissão e da profissionalidade docentes. Educação e Sociedade, Campinas, v. 25, n. 89, set.-dez, 2004.

MARTINS, A. M. A descentralização como eixo das reformas do ensino: uma discussão da literatura. Educação \& Sociedade, Revista de Ciência da Educação, Cedes, ano XXII, n. 77, p. 28-48, dez. 2001.

NÓVOA, António. O passado e o presente dos professores. In: NÓVOA, A. (Org.). Profissão professor. Porto, Portugal: Porto Editora, 1999. p. 13-34.

\section{Profissão professor. Porto: Porto Editora, 1995.}

Para o estudo sócio-histórico da gênese e desenvolvimento da profissão docente. Trabalho \& Educação, v. 4, p. 109-139, 1991.

OLIVEIRA, Dalila A. As reformas educacionais e suas repercussões sobre o trabalho docente. In: OLIVEIRA, Dalila A. (Org.). Reformas educacionais na América Latina e os trabalhadores docentes. Belo Horizonte: Autêntica, 2003. p. 13-35.

PACHECO, José Augusto. Políticas de avaliação e qualidade da educação. Uma análise crítica no contexto da avaliação externa de escolas, em Portugal. Avaliação, Campinas e Sorocaba, v. 19, n. 2, p. 363-371, jul. 2014. 
PAPI, Silmara. Professores: formação e profissionalização. Araraquara: Junqueira \& Marin, 2005.

FOCANDO A NOTÍCIA. Professores concursados superam temporários e representam mais de $60 \%$ na Paraíba. 8 de maio de 2013. Disponível em: <http://www.focandoanoticia.com.br/ professores-concursados-superam-temporarios-e-representammais-de-60-na-paraiba/>. Acesso em: 21 mar. 2015.

TARDIF, Maurice. Os professores diante do saber: esboço de uma problemática do saber docente In: Saberes docentes e formação profissional. Petrópolis: Vozes, 2002. p. 31-55.
TARTUCE, Gisela Lobo B. P.; NUNES, Marina M. R.; ALMEIDA, Patrícia Cristina Albieri de. Alunos do ensino médio e atratividade da carreira docente no Brasil. Cadernos de Pesquisa, v. 40, n. 140, p. 445-477, maio-ago. 2010.

TARDIF, M.; LESSARD, C. O trabalho docente: elementos para uma teoria da docência como profissão de interações humanas. Petrópolis: Vozes, 2005.

Recebido em 30-09-2015.

Aprovado em 18-01-2017. 